\title{
APPLIED
}

COGNITIVE
PSYCHOLOGY

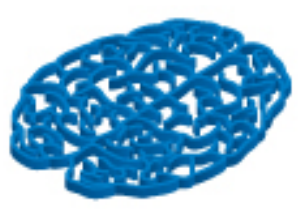

\section{Is the Seductive Details Effect Moderated by Mood? An Eye Tracking Study}

\begin{tabular}{|r|l|}
\hline Journal: & Applied Cognitive Psychology \\
\hline Manuscript ID & ACP-18-0090.R2 \\
\hline Wiley - Manuscript type: & Research Article \\
\hline Keywords: & $\begin{array}{l}\text { Seductive Details, Multimedia Learning, Mood, Eye Tracking, Decorative } \\
\text { Pictures }\end{array}$ \\
\hline
\end{tabular}

\section{SCHOLARONE ${ }^{\text {M }}$ \\ Manuscripts}




\section{Is the Seductive Details Effect Moderated by Mood? An Eye Tracking Study Introduction}

Seductive details are defined as "interesting, but unimportant information" (Garner, Gillingham, \& White, 1989, p. 41) that is usually related to the instructional content, but irrelevant for reaching the instructional goal (see also Harp \& Mayer, 1998; Mayer, 2005). For instance, attention-grabbing pictures or interesting text segments can serve as seductive details. The rationale for including this type of information into learning materials is to increase learners' motivation or interest in a topic (e.g., Schnotz, Fries, \& Horz, 2009). However, integrating seductive details into instructional materials has been shown to be detrimental to the learning outcome (seductive details effect; e.g., Harp \& Mayer, 1998).

One influential explanation for the seductive details effect is the attention distraction hypothesis (Harp \& Mayer, 1998), which states that seductive details draw away the attention of the learner from important (relevant) information (for a comprehensive overview of alternative accounts see Rey, 2012). As a consequence, unimportant information is processed at the expense of relevant instructional information. Evidence for this assumption comes from eye movement data based on the eye-mind hypothesis, which states that one can infer what a person is paying attention to from what that person is looking at (Just \& Carpenter, 1980). Applied to the study of seductive details, their attention-grabbing characteristics should reflect in corresponding eye movement patterns. Indeed, Chang and Choi (2014) found that the relative gaze duration on seductive details was negatively correlated to the relative gaze duration on relevant parts of the text. Moreover, relative gaze duration on seductive details was also negatively correlated to scores of recall and reading comprehension. In addition, a study by Lehman, Shraw, McCrudden, and Hartley (2007) measured reading times for relevant sentences and for seductive sentences and showed that time spent reading seductive sentences reduced the time spent reading sentences 
with essential information (for similar results see Rey, 2014; Sanchez \& Wiley, 2006). These findings indicate that by devoting attention to seductive details, attention is directed away from relevant information.

In our current research, we investigated a factor that might have an impact on distractibility and therefore on the seductive details effect, namely the emotional state or mood ${ }^{1}$ of the learners. In recent years, aspects of the instructional design influencing learners' emotions and its impact on learning have gained growing interest. This is, for instance, reflected in the Cognitive Affective Theory of Learning with Media (Moreno \& Mayer, 2007), a modification of Mayer's (2005) Cognitive Theory of Multimedia Learning, which incorporates affective, motivational, and metacognitive processes, but does not yet specify their impact on learning. More specifically, research on emotional design tests the hypothesis that the emotional valence of the instructional material itself and the arousal level it causes influences learners' mood which, in turn, affects learning performance. For example, an illustration in an instructional text depicting a kitten might cause the learners to experience positive emotions, which in turn might lead to higher motivation to continue reading and to learning gains. A couple of studies have shown such changes in processing of instructional material and its impact on the learning outcome. For instance, Um, Plass, Hayward, and Homer (2012; see also Plass, Heidig, Hayward, Homer, \& Um, 2014) used warm colors and round shapes in their instructional material, which induced positive emotions in learners and resulted in better comprehension and higher transfer performance compared to a control group with a neutral visual design.

Schneider, Dyrna, Meier, Beege, and Rey (2018; see also Schneider, Nebel, \& Rey, 2016) directly investigated emotional design in the context of seductive details. They contrasted

\footnotetext{
${ }^{1}$ We use the term mood to describe a low-level emotional episode, but do not intend to contrast it with terms such as affect and emotion, which are often used interchangeably (e.g., Otto, Euler, \& Mandel, 2000; Shuman \& Scherer, 2014).
} 
positively and negatively charged decorative pictures and additionally varied how closely related texts and pictures were. They found a seductive details effect only when the pictures were both negatively charged and loosely related to the text, whereas the presentation of positively charged and more strongly connected decorative pictures even benefitted retention. These findings indicate that the quality of decorative pictures moderates the seductive details effect and that affective processes may play a role here.

Another assumption regarding mood effects on cognitive processing that is relevant to the seductive details effect in general and to the attention distraction hypothesis in particular is that positive mood leads to an open mind set relative to neutral and negative mood (e.g., Ashby, Isen, \& Turken, 1999; Isen, 2009). An open mind set has several positive effects on cognitive processing in terms of increased creativity (e.g., Bolte, Goschke, \& Kuhl, 2003; Ashby, Isen, \& Turken, 1999; Isen, Daubman, \& Nowicki, 1987), more holistic processing (vs. local processing; e.g., Gasper \& Clore, 2002) and enhanced category learning (e.g., Nadler, Rabi, \& Minda, 2010). However, it is also suggested that an open mind set goes along with a broader attentional scope such that attentional filters are less selective (Rowe, Hirsch, \& Anderson, 2007), which may have a detrimental impact in the face of distraction (e.g., Dreisbach \& Goschke, 2004; Dreisbach, 2006, 2008; Rowe et al., 2007).

Basic research suggests that mood indeed has an impact on attentional scope and therefore might influence the processing of relevant and irrelevant stimuli within instructional materials. For instance, in a task-switching experiment a mild positive mood induced by positive pictures resulted in greater interference from novel distracters compared to a neutral mood (Dreisbach \& Goschke, 2004, Exp. 2). Furthermore, Rowe et al. (2007) demonstrated that participants in a 
positive mood showed increased visuospatial distraction in an Erikson flanker task ${ }^{2}$ compared to participants in a neutral or negative mood. They interpreted this result in terms of impaired selective attention, that is, a reduced capability for inhibitory filtering and increased attentional breadth (Rowe et al., 2007). In line with this, Biss, Hasher, and Thomas (2010) found better implicit memory for distractors superimposed on relevant stimuli for those participants who were in a more positive mood (as assessed by the Brief Mood Introspection Scale; Mayer \& Gaschke, 1988).

These findings thus support the idea that a more open mind set in a positive mood broadens the attentional scope and makes participants more susceptible to distraction, an assumption that is particularly interesting with respect to the aforementioned attention distraction hypothesis for the seductive details effect. It suggests that learners' mood may have an influence on their susceptibility to look at seductive details. Consequently, mood may moderate the seductive details effect such that the effect is stronger for participants in a positive mood because they are more easily distracted by interesting, but irrelevant information. Building on this work, we conducted an experiment, in which we manipulated the inclusion of seductive pictures as well as the emotional state of our participants (positive vs. negative). As dependent measures, we recorded eye movements (as well as learning outcomes) to investigate whether the increased distractibility in a positive mood extends to a learning setting. We predict that when reading a text with seductive pictures, positive mood compared to negative mood should lead to increased distractibility and therefore to more frequent fixations of and longer dwell times on the seductive pictures. Moreover, due to the assumption that more frequent and longer fixations on the seductive pictures lead to a reduced learning outcome performance, participants in the condition with seductive details who are in a positive mood should exhibit poorer text comprehension and

\footnotetext{
${ }^{2}$ In this flanker task, irrelevant stimuli appearing either left or right of the centrally displayed target have to be ignored.
} 
reduced memory for text content (but better memory for the seductive details) than participants in a negative mood.

\section{Experiment}

Our experiment was based on a $2 \times 2$ design with the between-subjects factors mood (positive vs. negative) and seductive details (instructional text with vs. without seductive pictures). Dependent measures were dwell times and number of fixations for the seductive pictures and the text as well as correct responses in a learning test. In addition, we measured picture recognition for the groups with seductive pictures. As a manipulation check, we further analyzed self-assessed mood prior to and after the learning phase.

\section{Method}

\section{Participants}

212 students from the University of Erfurt (Germany) took part in our study (155 female, 57 male; mean age 22.7; $S D=3.2)^{3}$. All of the participants spoke German as their first language. One participant had to be excluded due to technical problems. Participants were randomly assigned to one of the four experimental groups.

\section{Materials}

Mood Induction. As a meta-analysis revealed that the presentation of a film or story was the most effective procedure to induce both positive and negative mood states (Westermann, Spies, Stahl, \& Hesse, 1996), we presented short film sequences for mood induction. To induce a positive mood, we used a funny sequence from the movie "When Harry met Sally..." (Reiner \& Scheinman, 1989; German dubbing) that lasted approximately three minutes and to induce a negative mood, we showed a sad scene from the movie "The Bear" (Berri \& Annaud, 1988) lasting about four minutes.

\footnotetext{
${ }^{3}$ Ten additional students started to participate, but were excluded, because the calibration of the eye tracker was not successful.
} 
Instructional materials. We presented a text (1,084 words) explaining the findings of (neurological) research on sleep (“Anatomy of Sleep”, German: „Anatomie des Schlafes”; Simon, 2012). The text was presented on a computer screen and was distributed over five pages. It either included seductive pictures, which were interspersed throughout the text, or was presented as a text-only version (here the text was distributed evenly over the page). Figure 1 provides an example page of the instructional material in both versions.

Eleven purely illustrative pictures (e. g. a photo of an EEG, a schematic representation of the brain with arbitrary activation, Salvador Dali's surreal paintings of dreams ${ }^{4}$ ) served as seductive details. Though these pictures were somewhat related to the topic of the text, they should not contribute to its comprehension.

Measures. We measured text comprehension and retention of facts via ten single-choice questions with four answer choices each, for example "Which kind of frequencies are detected by the EEG just after falling asleep and before the first period of deep sleep? (a) Theta frequencies, (b) Delta frequencies, (c) A combination of alpha, beta, theta and delta frequencies, (d) Alpha frequencies" (correct answer in italics). For each correctly answered question, one point was given (maximum $=10$ points). A reliability test showed a low reliability for the learning test (10 questions; Cronbach's alpha $=.4$ ). Implications of the low reliability will be explicated in the discussion.

For the seductive details group, we additionally conducted a paper-and-pencil picture recognition test on which participants had to indicate the pictures they had seen (11 old and 29 new pictures).

In order to control for the success of mood induction, mood was assessed via a 9-point State of Pleasure scale of the Self-Assessment Manikin ranging from very sad (1) to very happy

${ }^{4}$ All materials are available upon request from the corresponding author. 
(9) (SAM; Lang, 1980). This scale allows to assess subjects' emotional state in a non-verbal way by presenting pictorial representations with the two poles of frowning (unhappy) and smiling (happy) figures.

\section{Procedure}

After signing the consent form, participants watched either the funny or the sad video clip, depending on mood condition. Immediately afterwards they had to assess their current mood on the SAM scale. Subsequently, the calibration of the eye tracker (SMI RED $120 \mathrm{~Hz}$ ) took place. Then the instructional materials were presented. Participants were instructed to read the text thoroughly and to navigate through the text at their own pace (it was not possible to return to a previous page). During study, eye movements were recorded. After reading the text, participants again indicated their momentary mood via the SAM scale. Subsequently, the learning test was administered. The test was computer based and the question order was randomized. Finally, in the group with seductive pictures, the picture recognition test took place. All sessions were individual sessions and lasted approximately 20 minutes. With the exception of the mood induction and the calibration phase, the experimenter was not present during the experiment, but was available at all times. All participants were offered the opportunity to sign up for a delayed debriefing via e-mail.

\section{Results}

Mood Manipulation Check. Following the procedure by Bower, Monteiro, and Gilligan (1978; see Rummer, Schweppe, Schlegelmilch, \& Grice, 2014; Storbeck \& Clore, 2005, for similar procedures), we intended to include only those participants whose scores matched the induced mood in the first measurement (calculated for the measurement directly after the mood induction and across both groups), that is, participants in the positive mood group with a score above the median SAM rating and participants in the negative mood group with scores below the 
median SAM rating. The resulting two mood groups were reliably different in the critical first SAM rating (positive: $M=7.6, S D=.56$; negative: $M=3.64, S D=1.08$; Mann-Whitney-UTest: $U=0.00, p<.001$ ) and in the second SAM rating after the learning phase (positive: $M=6.53, S D=1.05$; negative: $M=5.19, S D=.98 ; U=686, p<.001)$. However, this procedure resulted in a high number of to-be-excluded participants (90 of 211, Table 1 shows the distribution of participants over the four groups).

Therefore, we additionally analyzed the entire sample and will report further analyses both for the selected sample that is strictly controlled for mood (controlled sample) and for the entire sample (see Table 2 for distribution of participants). With the entire sample, mean SAM ratings directly after the mood induction were also significantly higher in the positive mood condition $(M=6.71, S D=1.22)$ than in the negative mood condition $(M=4.89, S D=1.76$; Mann-Whitney-U-Test: $U=2359.5, p<.001)$. Even though the difference between the SAM ratings after the reading phase was descriptively smaller, it still reached significance (positive mood condition: $M=6.19, S D=1.09$; negative mood condition: $M=5.6, S D=1.12$; MannWhitney-U-Test: $U=3979, p<.001$ ), indicating that the mood induction remained effective.

Gaze Patterns. To analyze the gaze patterns, two areas of interest (AOIs) were defined for each page: seductive pictures and text. Consequently, in the groups without seductive details only the text AOI could be defined. For each AOI, overall dwell time and number of fixations were calculated. As dependent measures, we calculated means for both AOIs and both measures (dwell time, number of fixations). Data points above or below 2.5 standard deviations were excluded from the analyses. This resulted in a data reduction of $1.9 \%$ for mean dwell time and $2.2 \%$ for the mean number of fixations. 
Means and standard deviations for dwell times and number of fixations on the pictures and the text as a function of affect and seductive details are displayed in Table 1 for the mood controlled sample $(N=121)$ and in Table 2 for the analysis with the entire sample $(N=211)$.

Pictures: Dwell Time. As expected, one-sided $t$-tests revealed that dwell time on the seductive pictures was longer under positive mood (controlled sample: $M=$ 4,706 $m s, S D=2,424$; entire sample: $M=4,138 m s, S D=1,742$ ) than under negative mood (controlled sample: $M=3,620 \mathrm{~ms}, S D=2,178$; entire sample: $M=3,469 \mathrm{~ms}, S D=1,758$ ). This difference was significant in both analyses (controlled sample: $t(57)=1.8, p=.039, \eta^{2}$ $=0.052$; entire sample: $t(97)=1.9, p=.03, \eta^{2}=0.035$.).

Pictures: Number of Fixations. Because fixations onto pictures in the seductive details group were not normally distributed, we calculated one-sided Mann-Whitney-U-Tests to compare the mean numbers of fixations. The results parallel those for mean dwell times. There was a significant difference between the positive (controlled sample: $M=15.23, S D=7.43$; entire sample: $M=13.1, S D=5.46$ ) and negative mood groups (controlled sample:

$M=11.37, S D=6.27$; entire sample: $M=11, S D=5.63$ ) regarding mean numbers of fixations onto the seductive pictures (controlled sample: $U=301, p=.023, \eta^{2}=0.067$; entire sample: $\left.U=985, p=.047, \eta^{2}=0.028\right)$.

Text: Dwell Time. With respect to dwell time on the text, a 2x2 ANOVA revealed no main effect for the factor mood neither in the analysis with the controlled sample (positive: $M=59,153 m s, S D=16,789$ vs. negative: $M=58,325 m s, S D=15,710, F<1)$ nor with the entire sample (positive $M=56,703 m s, S D=15,423$ vs. negative: $\left.M=58,996 m s, S D=15,150, F(1,207)=1.2, p=.27, \eta^{2}=0.006\right)$. The main effect for seductive details reached significance in the analysis with the entire sample such that participants spent more time on the text with seductive details $(M=60,966 m s, S D=14,516)$ than without 
seductive details $\left(M=55,145 m s, S D=15,527, F(1,207)=8.0, p=.005, \eta^{2}=0.037\right)$. In the analysis with the controlled sample, the pattern was similar, but the difference was not significant (with seductive details: $M=61,126 \mathrm{~ms}, S D=16,789$ vs. without seductive details: $\left.M=56,434 m s, S D=15,352, F(1,117)=2.57, p=.112, \eta^{2}=0.021\right)$. There was no interaction between these two factors (both $F s<1$ ).

To test whether the longer dwell time on the pictures for the positive mood group (compared to participants in a negative mood) in the condition with seductive details went along with shorter dwell time on the text, we additionally compared these two groups. However, this was not the case, as is indicated by a non-significant difference in the controlled sample (positive: $M=62,353 m s, S D=18,222$ vs. negative: $M=59,671 m s, S D=15,126, t<1)$ as well as in the entire sample (positive: $M=60,531 \mathrm{~ms}, S D=15,379$ and negative: $M=61,392 m s, S D=13,762, t<1)$. Similarly, mood did not affect mean dwell times on the text in the condition without seductive details, neither in the controlled sample (positive: $M=55,215 m s, S D=14,203$ vs. negative: $M=57,315 m s, S D=16,272, t<1$ ), nor in the entire sample (positive: $M=53,228 m s, S D=14,816$ vs. negative: $\left.M=56,930 m s, S D=16,083 ; t(110)=-1.26, p=.21, \eta^{2}=0.014\right)$.

Text: Number of Fixations. For fixations onto the text, a 2x2 ANOVA with the betweensubjects factors mood and seductive details indicated a significant main effect for seductive details. When the text was accompanied by seductive pictures, participants fixated the text more often than when they learned only with the text, as can be seen in the analyses, with the controlled sample (with seductive pictures: $M=191.42, S D=39.25$ vs. without: $\left.M=163.77, S D=33.44, F(1,117)=16.99, p<.001, \eta^{2}=0.13\right)$ and the entire sample (with seductive pictures: $M=191.06, S D=38.31$ vs. without: $M=161.44, S D=32.74 ; F(1,207)$ $\left.=36.65, p<.001, \eta^{2}=0.15\right)$. In contrast, mood did not affect the number of fixations in the 
controlled sample (positive: $M=180.11, S D=39.03$ vs. negative: $M=174.62, S D=38.71 ; F$ $<1$ ) or in the entire sample (positive: $M=173.93, S D=37.74$ vs. negative:

$M=176.68, S D=39.06 ; F<1)$. The interaction between mood and seductive details was also not significant (both $F s<1$ ).

As with dwell time, follow-up analyses indicated that there was no difference in fixations onto the text between participants in a positive and in a negative mood, both in the conditions with and without seductive pictures (all $t<1$ ).

Time on task. As dwell time on the texts and the pictures does not fully add up to time on task (e.g. it excludes gazes onto white space), we additionally report analyses on the log data ${ }^{5}$. The $2 \times 2$ ANOVAs revealed no main effect for mood in the controlled sample (positive: $M=379,570 m s, S D=10,1891$ vs. negative: $M=361,504 m s, S D=93,571 ; F<1)$ or in the entire sample (positive: $M=366,536 \mathrm{~ms}, S D=98,753$ vs. negative: $M=373,401 m s, S D=96,119 ; F<1)$. But there was a main effect for seductive pictures: Participants who learned with seductive pictures spent more time on the learning task than participants who learned with text only as the analyses for the controlled sample (with seductive pictures: $M=399,434 \mathrm{~ms}, S D=101,905$ vs. without: $M=342,320 \mathrm{~ms}, S D=85,269, F$ $\left.(1,115)=10.57, p=.002, \eta^{2}=0.084\right)$ and the entire sample indicate (with seductive pictures: $M=402,203 m s, S D=98,932$ vs. without: $M=341,663 m s, S D=86,686, F(1,205)$ $\left.=22.19, p<.001, \eta^{2}=0.098\right)$. The interaction between mood and seductive details was not significant (both $F \mathrm{~s}<1$ ).

Learning Test. Results of the learning test as a function of mood and seductive details can be found in Table 1 (controlled sample) and Table 2 (entire sample).

\footnotetext{
${ }^{5}$ For two participants, time on task data was not available due to technical problems.
} 
The 2x2 ANOVAs revealed no main effect for mood in the controlled sample (positive: $M=39.1 \%, S D=1.63$ and negative: $M=39.5 \%, S D=16.4, F<1)$ and in the entire sample (positive: $M=43.7 \%, S D=17.9$ vs. negative: $M=43 \%, S D=17.5, F<1$ ). The difference between the groups with and without seductive details reached significance in the controlled sample $\left(F(1,117)=11.99, p=.001, \eta^{2}=0.09\right)$, but only approached significance in the analysis of the entire sample $\left(F(1,207)=3.08, p=.08, \eta^{2}=0.015\right)$. Crucially, however, the direction of this difference contrasted with our expectations, as participants who learned with seductive details scored higher than participants in the group without seductive details both in the controlled sample (with seductive details: $M=44.7 \%, S D=17.1$ vs. without seductive details: $M=34.2 \%, S D=16.7$ ) and in the entire sample (with seductive details: $M=45.6 \%, S D=15.9$ vs. without: $M=41.3 \%, S D=19)$. Also, contrary to our expectations, the interaction between mood and seductive details did not reach significance (controlled sample: $F<1$; entire sample: $F$ $\left.(1,207)=1.24, p=.27, \eta^{2}=0.006\right)$.

Picture Recognition Test. Scores in the picture recognition test were calculated by subtracting the false alarm rate from the hit rate. The results of the picture recognition tests are displayed in Table 1 (controlled sample) and Table 2 (entire sample). Data of three participants in the controlled sample (plus two more in the entire sample) could not be included in the analysis, because they failed to fill out the picture recognition test sheet. Even though participants in a positive mood spent more time on the pictures, their recognition scores did not differ significantly from those in a negative mood in the controlled sample (positive: $M=0.56, S D=0.20$, negative: $\left.M=0.48, S D=0.21, t(53)=1.35, p=.18, \eta^{2}=0.037\right)$ as well as in the entire sample (positive: $M=0.54, S D=0.20$, negative: $M=0.51, S D=0.21, t<1$ ). Relationships between Reading Time and Learning Test (Explorative Analysis). To explore whether the better learning outcome for the group with seductive details can be attributed 
to longer reading times, we calculated an ANCOVA with the covariate dwell time on text. The 2x2 ANCOVAs revealed no main effect for mood (both $F<1$ ). The difference between the groups with and without seductive details remained significant in the controlled sample $(F$ $\left.(1,117)=10.39, p=.002, \eta^{2}=0.082\right)$. In the analysis of the entire sample this effect was again not significant $\left(F(1,207)=2.23, p=.14, \eta^{2}=0.011\right)$. The covariate did not contribute significantly to explaining learning test results (controlled sample: $F(1,117)=2.24, p=.138$, $\eta^{2}=0.019$; entire sample: $\left.F(1,207)=1.43, p=.233, \eta^{2}=0.007\right)$.

\section{Discussion}

We had predicted increased distractibility in positive compared to negative mood, which should manifest itself in longer viewing times for irrelevant pictures and translate to a larger seductive details effect. The expected pattern indeed showed up in the eye movement data: Participants in a positive mood looked both longer and more often at the seductive pictures than participants in a negative mood. Moreover, the difference was reliable irrespective of whether only those participants were included whose mood matched the mood induction condition or whether all participants were included in the two mood conditions. These findings can be interpreted such that the pictures attracted learners' attention more strongly when they were in a positive mood. Our results thus corroborate previous findings from basic research in an applied setting. They are in line with the hypothesis that positive mood is related to a more open mind set, which brings along many advantages (such as increases in creativity), but also entails increased distractibility. These findings also indicate that eye movement data can provide an online measure of distractibility in the context of learning with text and seductive pictures. Applying eye-tracking procedures in future studies may bring further insight into the cognitive processes involved in learning with seductive details. 
Contrary to our expectations, however, the increased distractibility visible in the gaze patterns did not translate into a stronger seductive details effect in the learning test. What is more, we did not observe any seductive details effect at all. Instead, in the controlled sample, the inclusion of the pictures resulted in better learning scores overall, while the analysis with the entire sample shows a descriptive, but non-significant advantage in the same direction. As this reversed seductive details effect was restricted to one analysis, it should be interpreted with caution. Nonetheless, the analyses converge in that there was definitely no disadvantage for the groups with seductive pictures.

Why did the greater distractibility in positive mood not result in a greater seductive details effect or rather not in a seductive details effect at all? It may be that certain aspects of our method are responsible for this unexpected finding. We will discuss these in the following.

For one, the learning materials could be problematic. With respect to the text materials, we do not see an indication that it differed from other learning materials in mayor aspects, as it was a popular scientific text of regular length $(1,084$ words that took participants approximately 6 minutes to read). A more critical issue might be the pictures. For one, they could have been less irrelevant than intended and may have fostered comprehension. However, what was depicted were a portrait of Ernst Kohlschütter, Salvador Dali's surreal paintings of dreams, or random EEG waves, which are only very loosely related to the contents of the text.

The study by Schneider et al. (2018) directs attention to another feature of decorative pictures, namely their affective charge. They found that positive decorative pictures increased learners' positive emotions and even improved learning performance when they were also semantically related to the text. We intended our decorative pictures to be rather neutral, but as we did not pretest them for valence, they may nonetheless have inadvertently improved learners' 
mood. However, an explorative analysis of the change in SAM ratings (prior to vs. after the learning phase) as a function of seductive details and mood does not support this idea ${ }^{6}$.

Given that 5 of the 11 pictures had a neuroscientific background (an EEG cap, EEG waves, brain images), a finding from science understanding may also be of interest here. It has been demonstrated that student participants judge scientific texts as more scientific and credible, when they are augmented by brain images even though these images did not convey any additional information compared to control conditions with other images or tables (McCabe \& Castel, 2008). The inclusion of these decorative pictures may therefore have led participants to take the learning text more seriously in the condition with decorative pictures. However, all these ideas are rather speculative and cannot be satisfactorily supported or discarded on the basis of the current data.

Alternatively, the pictures may have served to increase learners' motivation and interest in the learning topic, which was the main rationale for designers to include interesting, but irrelevant details such as pictures in the first place (e.g., Schnotz et al., 2009). This might have occurred in our experiment. At first glance, our data do support this hypothesis since learners dwell time on text was longer in the seductive pictures condition than in the condition without seductive pictures - even though this difference reached significance only in the analysis with the controlled sample. However, an explorative ANCOVA does not support this post-hoc assumption as the inclusion of dwell time on the text as a covariate did not alter the findings. The significant

\footnotetext{
${ }^{6}$ A repeated measures ANOVA revealed no significant effect for time of measurement*seductive details both for the controlled sample (first SAM rating of group with seductive pictures: $M=5.76, S D=2.1$, second SAM rating: $M=5.76, S D=1.26$ and first SAM rating of group without seductive pictures: $M=5.32, S D=2.24$, second SAM rating: $M=5.9, S D=1.17, F(1,117)=1.51, p=.22, \eta^{2}=0.013$ ) and for the entire sample (first SAM rating of group with seductive pictures: $M=5.96, S D=1.74$, second SAM rating: $M=5.95, S D=1.17$ and first SAM rating of group without seductive pictures: $M=5.62, S D=1.79$, second rating: $\left.M=5.48, S D=1.11, F(1,207)=1.34, p=.25, \eta^{2}=0.006\right)$.
} 
reversed seductive details effect in the analysis with the controlled sample can therefore not be attributed to participants in the condition with pictures taking more time to look at the text.

A few other aspects of the instructional material used in this experiment might have caused the absence of a seductive details effect. It may be the case that irrelevant pictures are particularly harmful when they are interspersed with relevant pictures as this should make it harder for participants to differentiate between relevant and irrelevant visual information compared to materials like the ones applied here, in which none of the pictures were relevant. However, this aspect of the materials has not yet been tested as a moderator of the seductive details effect and while relevant pictures are included in some studies on seductive details (e.g., Harp \& Mayer, 1998; Rey, 2014), this is not always the case (e.g., Sanchez \& Wiley, 2006; Park \& Lim, 2007).

Other aspects of our method may be more promising candidates for explaining the nonexistent seductive details effect. The aforementioned meta-analysis by Rey (2012) found a medium-sized mean effect for transfer $(d=0.48)$, but only a small mean effect for retention as the dependent variable $(d=0.3)$. Our learning test aimed to measure comprehension, but the low reliability of the scale questions this. The low correlations between the individual items may be due to the fact that the scale consisted only of ten items which can lead to an underestimation of reliability (Tavakol, 2011). Yet, they may also indicate that we measured retention of individual facts rather than overall comprehension and that our participants remembered the text in terms of isolated facts rather than in terms of an integrated mental model. If this were the case, memory of one fact as measured by one item would not be a good predictor of memory for other facts. This suggests that our dependent variable should be regarded as measuring retention rather than comprehension, for which only a small seductive details effect would be expected. In addition, performance was not very high overall (ranging from $33 \%$ to $44 \%$ correct in the 
controlled sample and from $40 \%$ to $47 \%$ correct in the entire sample) so that the retention test may have been too difficult to reliably detect small group differences.

Another methodological issue that may have weakened the chance to obtain a seductive details effect concerns the timing of the learning phase. A striking finding in the eye movement data is that even though participants in a positive mood spent more time looking at the pictures than participants in a negative mood, this did not result in a reverse effect for looking at the text. What is more, participants in the condition with seductive details spent even more time looking at the text than participants who learned solely with the text - even though this difference reached significance only in the analysis with the controlled sample. Nonetheless, these findings strongly indicate that even though the pictures attracted the learners' attention (and did so particularly for those in a positive mood), they did not attract attention away from the relevant parts of the learning materials. The negative impact of seductive details might thus be restricted to cases in which attention to them must come at a cost of attention to the actual learning material, that is when text and decorative pictures do not only compete for attention, but also for time. Since the learners in our experiment could determine the speed at which they proceeded, they did not need to process the pictures at the expense of the text. Rey's (2012) meta-analysis of the seductive details effect gives further evidence for the idea that competition for processing time might be a necessary precondition for competition for attention to negatively impact learning: restricted timing in the learning phase yielded significantly larger effect sizes in retention tests in comparison to unrestricted timing $(d=0.55$ vs. $d=0.04)$, the latter of which did not result in a seductive details effect at all. This indicates that allowing learners to determine the pace at which they process the instructional material makes a seductive details effect less likely to occur.

\section{Conclusion}


Our results support the assumption that positive mood leads to increased distractibility, as was shown in basic research paradigms (e.g., Dreisbach \& Goschke, 2004) and could be translated to a more applied setting in the current study: The eye tracking data showed that a positive mood induction led to longer and more frequent looks on interesting, but irrelevant pictures than a negative mood induction. However, there were no significant effects of mood or seductive details on learning outcome.

Therefore, to answer the question whether mood moderates the seductive details effect, further research is necessary that uses learning materials, dependent measures, and an experimental procedure that increase the probability to find a seductive details effect in the first place - that may then be moderated by learners' mood. One way to address this would be to use materials with which a reliable seductive details effect is found and to add a mood manipulation (but see Kühl, Moersdorf, Römer, \& Münzer, accepted; for no seductive details effect with established materials).

With respect to the distraction hypothesis (Harp \& Mayer, 1998), our findings suggest that shifts of attention towards seductive details may be problematic only, when they entail shifts away from relevant learning material, but not when they can be compensated by spending more time with the material overall. 


\section{References}

Ashby, F. G., Isen, A. M., \& Turken, U. (1999). A neuropsychological theory of positive affect and its influence on cognition. Psychological Review, 106, 529-550. doi: 10.1037/0033295X.106.3.529

Berri, C. (Producer), \& Annaud, J. J. (Director). (1988). L'Ours [Motion Picture]. France: Renn. Biss, R. K., Hasher, L., \& Thomas, R. C. (2010). Positive mood is associated with the implicit use of distraction. Motivation and Emotion, 34(1), 73-77. doi: 10.1007/s11031-010-9156$\mathrm{y}$

Bolte, A., Goschke, T., \& Kuhl, J. (2003). Emotion and intuition: Effects of positive and negative mood on implicit judgments of semantic coherence. Psychological Science, 14(5), 416421. doi: $10.1111 / 1467-9280.01456$

Bower, G. H., Monteiro, K. P., \& Gilligan, S. G. (1978). Emotional mood as a context for learning and recall. Journal of Verbal Learning \& Verbal Behavior, 17, 573-585. doi:10.1016/S0022-5371(78)90348-1

Chang, Y., \& Choi, S. (2014). Effects of seductive details evidenced by gaze duration. Neurobiology of Learning and Memory, 109, 131-138. doi: 10.1016/j.nlm.2014.01.005

Dreisbach, G. (2006). How positive affect modulates cognitive control: The costs and benefits of reduced maintenance capability. Brain and Cognition, 60, 11-19. doi: 10.1016/j.bandc. 2005.08 .003

Dreisbach, G. (2008). Wie Stimmungen unser Denken beeinflussen. Report Psychologie, 33, 290298. 
Dreisbach, G. \& Goschke, T. (2004). How positive affect modulates cognitive control: Reduced perseveration at the cost of increased distractibility. Journal of Experimental Psychology: Learning, Memory, \& Cognition. 30, 343-353. doi: 10.1037/0278-7393.30.2.343

Garner, R., Gillingham, M. G., \& White, C. S. (1989). Effects of 'seductive details' on macroprocessing and microprocessing in adults and children. Cognition and Instruction, 6(1), 41-57. doi: 10.1207/s1532690xci0601_2

Gasper, K., \& Clore, G. L. (2002). Attending to the big picture: Mood and global versus local processing of visual information. Psychological Science, 13(1), 34-40. doi: 10.1111/14679280.00406

Harp, S. F., \& Mayer, R. E. (1998). How seductive details do their damage: A theory of cognitive interest in science learning. Journal of Educational Psychology, 90, 414-434. doi: 10.1037/0022-0663.90.3.414

Isen, A. M. (2009). A role for neuropsychology in understanding the facilitating influence of positive affect on social behavior and cognitive processes. In S. Lopez \& C. R. Snyder (Eds.), Oxford handbook of positive psychology (2nd ed., pp. 503-518). New York, NY: Oxford University Press.

Isen, A. M., Daubman, K. A., \& Nowicki, G. P. (1987). Positive affect facilitates creative problem solving. Journal of Personality and Social Psychology, 52(6), 1122-1131. doi: $10.1037 / 0022-3514.52 .6 .1122$

Just, M. A., \& Carpenter, P. A. (1980). A theory of reading: From eye fixations to comprehension. Psychological Review, 87, 329-354. doi: 10.1037/0033-295X.87.4.329

Kühl, T., Moersdorf, F., Römer, M., \& Münzer, S. (accepted). Adding emotionality to seductive details - Consequences for learning?. Applied Cognitive Psychol. https://doi.org/10.1002/acp.3477 
Lang, P. J. (1980). Behavioral Treatment and Bio-Behavioral Assessment: Computer Applications. In J. B. Sidowski, J. H. Johnson, \& T. A. Williams (Eds.), Technology in mental health care delivery systems (pp. 119-1 37). Norwood, NJ: Ablex.

Lehman, S., Schraw, G., McCrudden, M. T., \& Hartley, K. (2007). Processing and recall of seductive details in scientific text. Contemporary Educational Psychology, 32, 569-587. doi: 10.1016/j.cedpsych.2006.07.002

Mayer, R. E. (2005). Principles for reducing extraneous processing in multimedia learning: Coherence, signaling, redundancy, spatial contiguity, and temporal contiguity principles. In R. E. Mayer (Ed.), The Cambridge handbook of multimedia learning, (pp. 183-200). Cambridge: Cambridge University Press.

Mayer, J. D., \& Gaschke, Y. N. (1988). The experience and metaexperience of mood. Journal of Personality and Social Psychology, 55, 102-111.

McCabe, D. P., \& Castel, A. D. (2008). Seeing is believing: The effect of brain images on judgments of scientific reasoning. Cognition, 107(1), 343-352. doi: 0.1016/j.cognition.2007.07.017

Moreno, R., \& Mayer, R. (2007). Interactive multimodal learning environments. Educational Psychology Review, 19(3), 309-326. doi: 10.1007/s10648-007-9047-2

Nadler, R. T., Rabi, R., \& Minda, J. P. (2010). Better mood and better performance: Learning rule-described categories is enhanced by positive mood. Psychological Science, 21(12), 1770-1776. doi: 10.1177/0956797610387441

Otto, J., Euler, H. A., \& Mandl, H. (2000). Begriffsbestimmungen. In J. Otto, H. A. Euler und H. Mandl (Eds.), Handbuch Emotionspsychologie (p. 11-18). Weinheim: Beltz, Psychologie Verlags Union. 
Park, S., \& Lim, J. (2007). Promoting positive emotion in multimedia learning using visual illustrations. Journal of Educational Multimedia and Hypermedia, 16, 141-162.

Plass, J. L., Heidig, S., Hayward, E. O., Homer, B. D., \& Um, E. (2014). Emotional design in multimedia learning: Effects of shape and color on affect and learning. Learning and Instruction, 29, 128-140. doi: 10.1016/j.learninstruc.2013.02.006

Reiner, R. (Producer \& Director) \& Scheinman, A. (Producer). (1989). When Harry Met Sally [Motion Picture]. USA: Metro-Goldwyn-Mayer.

Rey, G. D. (2012). A review of research and a meta-analysis of the seductive detail effect. Educational Research Review, 7(3), 216-237. doi: 10.1016/j.edurev.2012.05.003

Rey, G. D. (2014). Seductive details and attention distraction-An eye tracker experiment. Computers in Human Behavior, 32, 133-144. doi: 10.1016/j.chb.2013.11.017

Rowe, G., Hirsh, J. B., \& Anderson, A. K. (2007). Positive affect increases the breadth of attentional selection. Proceedings of the National Academy of Sciences, 104(1), 383-388. doi: $10.1073 /$ pnas.0605198104

Rummer, R., Schweppe, J., Schlegelmilch, R., \& Grice, M. (2014). Mood is linked to vowel type: The role of articulatory movements. Emotion, 14, 246. doi: 10.1037/a0035752

Sanchez, C. A., \& Wiley, J. (2006). An examination of the seductive details effect in terms of working memory capacity. Memory \& Cognition, 34, 344-355. doi: 10.3758/BF03193412

Schneider, S., Dyrna, J., Meier, L., Beege, M., \& Rey, G. D. (2018). How affective charge and text-picture connectedness moderate the impact of decorative pictures on multimedia learning. Journal of Educational Psychology, 110(2), 233-249. doi: 10.1037/edu0000209

Schneider, S., Nebel, S., \& Rey, G. D. (2016). Decorative pictures and emotional design in multimedia learning. Learning and Instruction, 44, 65-73. doi:

10.1016/j.learninstruc.2016.03.002

http://mc.manuscriptcentral.com/acp 
Schnotz, W., Fries, S., \& Horz, H. (2009). Motivational aspects of cognitive load theory. In M. Wosnitza, S. A. Karabenick, A. Efklides, \& P. Nenniger (Eds.), Contemporary motivation research: From global to local perspectives (pp. 69-96). Göttingen and New York: Hogrefe \& Huber.

Shuman, V., \& Scherer, K. R. (2014). Concepts and structures of emotions. In R. Pekrun \& L. Linnenbrink-Garcia (Eds.), International Handbook of Emotions in Education (pp. 1335). New York, NY: Routledge.

Simon, N. (2012). Anatomie des Schlafes. Retrieved from http://dasgehirn.info/handeln/schlaftraum/anatomie-des-schlafes-9121/ (October, 12th 2018)

Storbeck, J., \& Clore, G. L. (2005). With sadness comes accuracy; with happiness, false memory: Mood and false memory effect. Psychological Science, 16, 785-791. doi:10.1111/j.14679280.2005.01615.x

Tavakol, M., \& Dennick, R. (2011). Making sense of Cronbach's alpha. International Journal of Medical Education, 2, 53-55. doi: 10.5116/ijme.4dfb.8dfd

Um, E., Plass, J. L., Hayward, E. O., \& Homer, B. D. (2012). Emotional design in multimedia learning. Journal of Educational Psychology, 104(2), 485. doi: 10.1037\%2Fa0026609

Westermann, R., Spies, K., Stahl, G., \& Hesse, F. W. (1996). Relative effectiveness and validity of mood induction procedures: A meta-analysis. European Journal of Social Psychology, 26(4), 557-580. doi: 10.1002/(SICI)1099-0992(199607)26:4<557::AIDEJSP769>3.0.CO;2-4

Wiley, J. (2003). Cognitive and educational implications of visually rich media: Images and imagination. In M. E. Hocks \& M. R. Kendrick (Eds.), Eloquent images: Word and Image in the Age of New Media (pp. 201-215). Cambridge, MA: MIT Press. 


\section{TABLES}

TABLE 1: Data of the analysis with the sample that was strictly controlled for mood $(\mathrm{N}=121)$ : number of participants $(\mathrm{N})$, dwell times (pictures and text), number of fixations (pictures and text), retention scores and picture recognition scores (standard deviations in parenthesis) as a function of mood and seductive details.

\begin{tabular}{|c|c|c|c|c|}
\hline & \multicolumn{2}{|c|}{ Positive Mood } & \multicolumn{2}{|c|}{ Negative Mood } \\
\hline & $\begin{array}{l}\text { With Seductive } \\
\text { Pictures }\end{array}$ & $\begin{array}{l}\text { Without Seductive } \\
\text { Pictures }\end{array}$ & $\begin{array}{l}\text { With Seductive } \\
\text { Pictures }\end{array}$ & $\begin{array}{l}\text { Without } \\
\text { Seductive } \\
\text { Pictures }\end{array}$ \\
\hline Number of Participants & $N=32$ & $N=26$ & $N=27$ & $N=36$ \\
\hline Dwell Time - Seductive Pictures in ms & $\begin{array}{l}M=21,791 \\
(S D=9,774)\end{array}$ & --- & $\begin{array}{l}M=15,376 \\
(S D=6,553)\end{array}$ & --- \\
\hline Dwell Time - Text in ms & $\begin{array}{l}M=62,353 \\
(S D=18,222)\end{array}$ & $\begin{array}{l}M=55,215 \\
(S D=14,203)\end{array}$ & $\begin{array}{l}M=59,671 \\
(S D=15,126)\end{array}$ & $\begin{array}{l}M=57,315 \\
(S D=16,272)\end{array}$ \\
\hline Number of Fixations - Seductive & $M=68.00$ & --- & $M=51.15$ & --- \\
\hline Pictures & $(S D=27.3)$ & & $(S D=25.31)$ & \\
\hline Number of Fixations - Text & $\begin{array}{l}M=195.3 \\
(S D=38.03)\end{array}$ & $\begin{array}{l}M=161.42 \\
(S D=31.96)\end{array}$ & $\begin{array}{l}M=186.83 \\
(S D=40.88)\end{array}$ & $\begin{array}{l}M=165.46 \\
(S D=34.82)\end{array}$ \\
\hline Scores Retention Test in \% & $\begin{array}{l}M=44.1 \\
(S D=19.0)\end{array}$ & $\begin{array}{l}M=33.1 \\
(S D=17.4)\end{array}$ & $\begin{array}{l}M=45.6 \\
(S D=14.8)\end{array}$ & $\begin{array}{l}M=35.0 \\
(S D=16.3)\end{array}$ \\
\hline $\begin{array}{l}\text { Scores Picture Recognition Test (hits } \\
\text { rate minus false alarms rate) }\end{array}$ & $\begin{array}{l}M=.56 \\
(S D=.20)\end{array}$ & --- & $\begin{array}{l}M=.48 \\
(S D=.21)\end{array}$ & --- \\
\hline Time on task in ms & $\begin{array}{l}M=412,669 \\
(S D=110,719)\end{array}$ & $\begin{array}{l}M=379,570 \\
(S D=101,891)\end{array}$ & $\begin{array}{l}M=384,238 \\
(S D=90,405)\end{array}$ & $\begin{array}{l}M=343,966 \\
(S D=93,442)\end{array}$ \\
\hline
\end{tabular}


TABLE 2: Data of the analysis with entire sample $(N=211)$ : number of participants $(\mathrm{N})$, dwell times (pictures and text), number of fixations (pictures and text), retention scores and picture recognition scores (standard deviations in parenthesis) as a function of mood and seductive details.

\section{Positive Mood Negative Mood}

\begin{tabular}{|c|c|c|c|c|}
\hline & $\begin{array}{l}\text { With Seductive } \\
\text { Pictures }\end{array}$ & $\begin{array}{c}\text { Without Seductive } \\
\text { Pictures }\end{array}$ & $\begin{array}{c}\text { With Seductive } \\
\text { Pictures }\end{array}$ & $\begin{array}{l}\text { Without } \\
\text { Seductive } \\
\text { Pictures }\end{array}$ \\
\hline Number of Participants & $N=49$ & $N=54$ & $N=50$ & $N=58$ \\
\hline Dwell Time - Seductive Pictures in ms & $\begin{array}{l}M=4,138 \\
(S D=1,742)\end{array}$ & --- & $\begin{array}{l}M=3,469 \\
(S D=1,758)\end{array}$ & --- \\
\hline Dwell Time - Text in ms & $\begin{array}{l}M=60,531 \\
(S D=15,379)\end{array}$ & $\begin{array}{l}M=53,228 \\
(S D=14,816)\end{array}$ & $\begin{array}{l}M=61,392 \\
(S D=13,762)\end{array}$ & $\begin{array}{l}M=56,930 \\
(S D=16,083)\end{array}$ \\
\hline $\begin{array}{l}\text { Number of Fixations - Seductive } \\
\text { Pictures }\end{array}$ & $\begin{array}{l}M=13.1 \\
(S D=5.46)\end{array}$ & --- & $\begin{array}{l}M=11.04 \\
(S D=5.63)\end{array}$ & --- \\
\hline Number of Fixations - Text & $\begin{array}{l}M=190.73 \\
(S D=34.57)\end{array}$ & $\begin{array}{l}M=158.68 \\
(S D=34.06)\end{array}$ & $\begin{array}{l}M=191.39 \\
(S D=42)\end{array}$ & $\begin{array}{l}M=164 \\
(S D=31.54)\end{array}$ \\
\hline Scores Retention Test in \% & $\begin{array}{l}M=47.3 \\
(S D=16.6)\end{array}$ & $\begin{array}{l}M=40.4 \\
(S D=18.6)\end{array}$ & $\begin{array}{l}M=43.8 \\
(S D=15.2)\end{array}$ & $\begin{array}{l}M=42.2 \\
(S D=19.4)\end{array}$ \\
\hline $\begin{array}{l}\text { Scores Picture Recognition Test (hits } \\
\text { rate minus false alarms rate) }\end{array}$ & $\begin{array}{l}M=.54 \\
(S D=.20)\end{array}$ & --- & $\begin{array}{l}M=.5 \\
(S D=.22)\end{array}$ & --- \\
\hline Time on task in ms & $\begin{array}{l}M=401,949 \\
(S D=103,323)\end{array}$ & $\begin{array}{l}M=335,058 \\
(S D=83,499)\end{array}$ & $\begin{array}{l}M=402,448 \\
(S D=95,579)\end{array}$ & $\begin{array}{l}M=347,921 \\
(S D=89,889)\end{array}$ \\
\hline
\end{tabular}


1

2

3

4

5

6

7

8

9

10

11

12

13

14

15

16

17

18

19

20

21

22

23

24

25

26

27

28

29

30

31

32

33

34

35

36

37

38

39

40

41

42

43

44

45

46

47

48

49

50

51

52

53

54

55

56

57

58

59

60

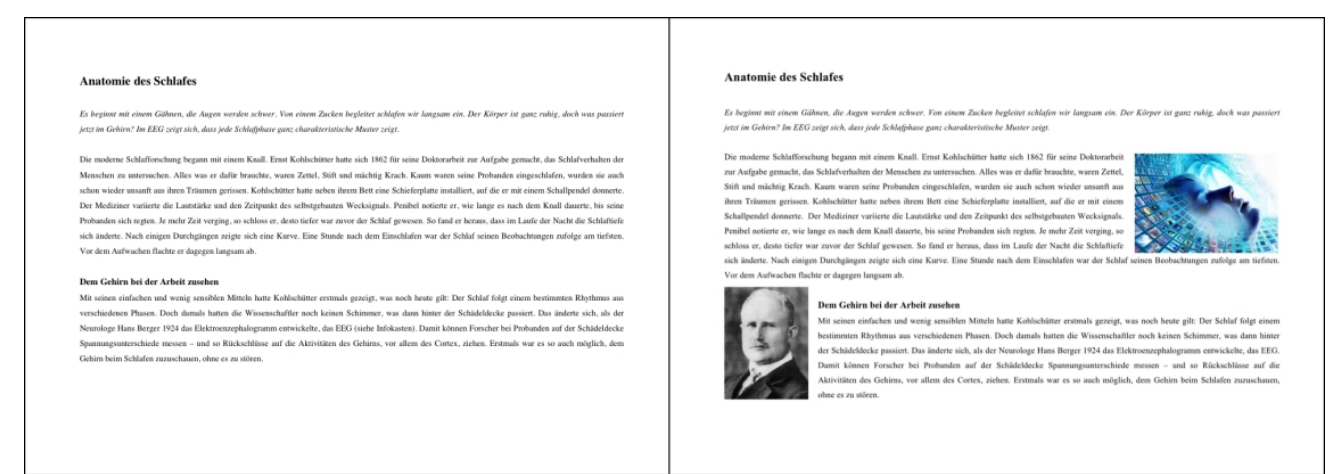

Example pages from the instructional text: page 1 of 5 without and with seductive pictures. 